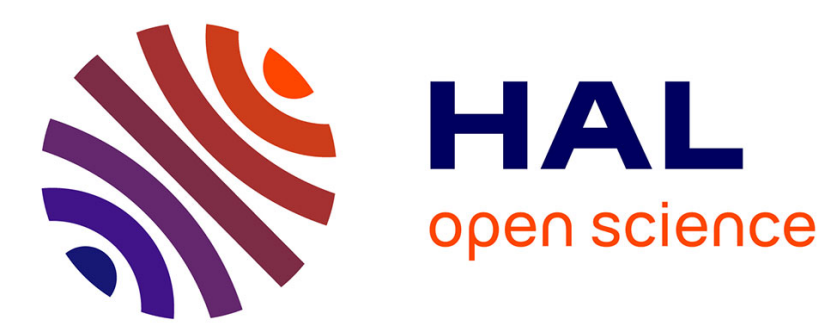

\title{
Corrections to: "On Lévy processes conditioned to stay positive"
}

Loïc Chaumont, R.-A. Doney

\section{To cite this version:}

Loïc Chaumont, R.-A. Doney. Corrections to: "On Lévy processes conditioned to stay positive". Electronic Journal of Probability, 2008, 13 (1), pp.1 - 4. 10.1214/EJP.v13-466 . hal-03031596

\section{HAL Id: hal-03031596 \\ https://univ-angers.hal.science/hal-03031596}

Submitted on 30 Nov 2020

HAL is a multi-disciplinary open access archive for the deposit and dissemination of scientific research documents, whether they are published or not. The documents may come from teaching and research institutions in France or abroad, or from public or private research centers.
L'archive ouverte pluridisciplinaire HAL, est destinée au dépôt et à la diffusion de documents scientifiques de niveau recherche, publiés ou non, émanant des établissements d'enseignement et de recherche français ou étrangers, des laboratoires publics ou privés. 


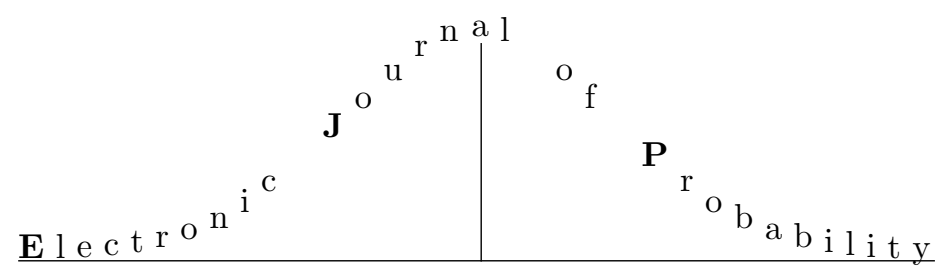

Vol. 13 (2008), Paper no. 1, pages 1-4.

Journal URL

http://www.math.washington.edu/ ejpecp/

\title{
Corrections to "On Lévy processes conditioned to stay positive"
}

\author{
L. Chaumont \\ LAREMA, Université d'Angers \\ 2 boulevard Lavoisier \\ 49045 Angers Cedex 01 \\ E-mail: loic.chaumont@univ-angers.fr \\ http://math.univ-angers.fr/perso/ chaumont \\ R. A. Doney \\ Department of Mathematics \\ University of Manchester \\ Oxford Road, M13 9PL, Manchester \\ E-mail:rad@maths.manchester.ac.uk \\ http://www . maths . manchester .ac .uk/DeptWeb/Homepages/rad
}

\begin{abstract}
We correct two errors of omission in our paper, [2] .

Key words: Lévy process conditioned to stay positive, weak convergence, excursion measure.
\end{abstract}

AMS 2000 Subject Classification: Primary 60G51, 60G17.

Submitted to EJP on September 25, 2007, final version accepted December 18, 2007. 
We would like to correct two errors of omission in our paper, [2]. The first occurs in equation (2.4), where we overlooked the possibility that the downgoing ladder time process has a positive drift. This happens if and only if 0 is not regular for $(0, \infty)$. If this drift is denoted by $\eta$, the correct version of $(2.4)$ is

$$
\begin{gathered}
\mathbb{P}_{x}\left(\tau_{(-\infty, 0)}>\mathbf{e} / \varepsilon\right)=\mathbb{P}\left(\underline{X}_{\mathbf{e} / \varepsilon} \geq-x\right) \\
=\mathbb{E}\left(\int_{[0, \infty)} e^{-\epsilon t} \mathbb{I}_{\left\{\underline{X}_{t} \geq-x\right\}} d \underline{L}_{t}\right)[\eta \varepsilon+\underline{n}(\mathbf{e} / \varepsilon<\zeta)],
\end{gathered}
$$

and the correct version of $(2.5)$ is:

$$
h(x)=\lim _{\varepsilon \rightarrow 0} \frac{\mathbb{P}_{x}\left(\tau_{(-\infty, 0)}>\mathbf{e} / \varepsilon\right)}{\eta \varepsilon+\underline{n}(\mathbf{e} / \varepsilon<\zeta)} .
$$

However this makes no essential difference to the proof of the following Lemma 1: we just need to replace $\underline{n}\left(\mathbf{e}_{\varepsilon}<\zeta\right)$ by $\eta \varepsilon+\underline{n}\left(\mathbf{e}_{\varepsilon}<\zeta\right)$ four times, and $\underline{n}(\zeta)$ by $\eta+\underline{n}(\zeta)$ in (2.6). The details can be seen in section 8.2 of [3]. We should also mention that (1) can be found in [1]: see equation (8), p 174 .

The second omission is that we failed to give any proof of

Corollary 1. Assume that 0 is regular upwards. For any $t>0$ and for any $\mathcal{F}_{t}$-measurable, continuous and bounded functional $F$,

$$
\underline{n}(F, t<\zeta)=k \lim _{x \rightarrow 0} \mathbb{E}_{x}^{\uparrow}\left(h\left(X_{t}\right)^{-1} F\right) .
$$

The clear implication from our paper is that this follows immediately from our main result, Theorem 2 , but this overlooks the singularity at zero of the function $1 / h(x)$. Since this Corollary has been cited in a number of recent papers, we give here a full proof of it.

Proof. From (3.2) and Theorem 2 of [2] we see that, for any fixed $\delta>0, t>0$,

$$
\underline{n}\left(F, t<\zeta, X_{t}>\delta\right)=k \lim _{x \rightarrow 0} \mathbb{E}_{x}^{\uparrow}\left(h\left(X_{t}\right)^{-1} F, X_{t}>\delta\right),
$$

and in particular, taking $F \equiv 1$,

$$
\begin{aligned}
\underline{n}\left(t<\zeta, X_{t}>\delta\right) & =k \lim _{x \rightarrow 0} \mathbb{E}_{x}^{\uparrow}\left(h\left(X_{t}\right)^{-1}, X_{t}>\delta\right) \\
& =k \lim _{x \rightarrow 0} \mathbb{P}_{x}\left(X_{t}>\delta, \tau_{(-\infty, 0)}>t\right) / h(x) .
\end{aligned}
$$

Suppose we can show that

$$
\underline{n}(t<\zeta)=k \lim _{x \rightarrow 0} \mathbb{P}_{x}\left(\tau_{(-\infty, 0)}>t\right) / h(x) .
$$

Then, by subtraction,

$$
\begin{aligned}
\underline{n}\left(t<\zeta, X_{t} \leq \delta\right) & =k \lim _{x \rightarrow 0} \mathbb{P}_{x}\left(X_{t} \leq \delta, \tau_{(-\infty, 0)}>t\right) / h(x) \\
& =k \lim _{x \rightarrow 0} \mathbb{E}_{x}^{\uparrow}\left(h\left(X_{t}\right)^{-1}, X_{t} \leq \delta\right) .
\end{aligned}
$$


Since $\underline{n}\left(t<\zeta, X_{t}=0\right)=0$, if $K$ is an upper bound for $F$, we also have

$$
\lim _{\delta \rightarrow 0} \underline{n}\left(F, t<\zeta, X_{t} \leq \delta\right) \leq K \lim _{\delta \rightarrow 0} \underline{n}\left(t<\zeta, X_{t} \leq \delta\right)=0,
$$

and the required conclusion follows.

To prove (3) we start with (1), and, since we are assuming that 0 is regular upwards, the drift $\eta$ in the downwards ladder time process is zero, so we can write it as

$$
\int_{0}^{\infty} e^{-\varepsilon t} \mathbb{P}_{x}\left(\tau_{(-\infty, 0)}>t\right) d t=h^{(\varepsilon)}(x) \int_{0}^{\infty} e^{-\varepsilon t} \underline{n}(\zeta>t) d t,
$$

where $h^{(\varepsilon)}(x)=\mathbb{E}\left(\int_{0}^{\infty} e^{-\varepsilon t} \mathbb{I}_{\underline{X}_{t} \geq-x} d L_{t}\right)$. We know $0 \leq h^{(\varepsilon)}(x) \leq h(x)$, so

$$
\int_{0}^{\infty} e^{-\varepsilon t} \mathbb{P}_{x}\left(\tau_{(-\infty, 0)}>t\right) d t \leq h(x) \int_{0}^{\infty} e^{-\varepsilon t} \underline{n}(\zeta>t) d t .
$$

But we also have

$$
\begin{aligned}
\liminf \operatorname{Pin}_{x \downarrow 0} \frac{\mathbb{P}_{x}\left(\tau_{(-\infty, 0)}>t\right)}{h(x)} & \geq \lim _{\delta \downarrow 0} \lim _{x \downarrow 0} \frac{\mathbb{P}_{x}\left(\tau_{(-\infty, 0)}>t, X_{t}>\delta\right)}{h(x)} \\
& =\lim _{\delta \downarrow 0} \underline{n}\left(\zeta>t, X_{t}>\delta\right)=\underline{n}(\zeta>t) .
\end{aligned}
$$

Together, these prove that

$$
\lim _{x \downarrow 0} \int_{0}^{\infty} e^{-\varepsilon t} \frac{\mathbb{P}_{x}(\tau(-\infty, 0)>t) d t}{h(x)}=\int_{0}^{\infty} e^{-\varepsilon t} \underline{n}(\zeta>t) d t .
$$

Thus the measure with density $\mathbb{P}_{x}\left(\tau_{(-\infty, 0)}>t\right) / h(x)$ converges weakly to the measure with the continuous density $\underline{n}(\zeta>t)$. But if $0<c<t$ are fixed we have

$$
\begin{aligned}
\lim _{x \rightarrow 0} \mathbb{P}_{x}\left(\tau_{(-\infty, 0)}\right. & >t) / h(x) \geq c^{-1} \lim _{x \rightarrow 0} \int_{t}^{t+c} \mathbb{P}_{x}\left(\tau_{(-\infty, 0)}>s\right) d s / h(x) \\
& =c^{-1} \int_{t}^{t+c} \underline{n}(\zeta>s) d s \geq \underline{n}(\zeta>t+c), \\
\lim _{x \rightarrow 0} \mathbb{P}_{x}\left(\tau_{(-\infty, 0)}\right. & >t) / h(x) \leq c^{-1} \lim _{x \rightarrow 0} \int_{t-c}^{t} \mathbb{P}_{x}\left(\tau_{(-\infty, 0)}>s\right) d s / h(x) \\
& =c^{-1} \int_{t-c}^{t} \underline{n}(\zeta>s) d s \leq \underline{n}(\zeta>t-c),
\end{aligned}
$$

and letting $c \downarrow 0$ we conclude that (3) holds, and hence the Corollary.

Acknowledgement We thank Erik Baurdoux and Mladen Savov for bringing these errors to our attention. 


\section{References}

[1] J. Bertoin. Lévy Processes. Cambridge University Press, Cambridge, (1996). MR1406564

[2] L. Chaumont and R. A. Doney. On Lévy processes conditioned to stay positive. Electronic J. Probab., 10, 948-961, (2005). MR2164035

[3] R. A. Doney. Fluctuation Theory for Lévy Processes. Lecture Notes in Math. 1897, Springer, Berlin, (2007). MR2320889 